\title{
GLÓRIA FEITA DE SÁTIRA: A GRANDE GUERRA DE MARIO MONICELLI
}

\begin{abstract}
Ana Carolina Fernandes ${ }^{1}$
Resumo: Esse trabalho pretende investigar o filme A grande guerra (1959), do diretor italiano Mario Monicelli. Acusado de anti-patriotismo à época de seu lançamento, a obra revisita os conflitos da Primeira Guerra Mundial em um registro cínico e tragicômico. Monicelli é considerado um dos nomes mais expressivos do gênero das Commedia all'italiana, um estilo popular que dominou o cinema italiano nas décadas de 60 e 70, caracterizado pela crítica social e sátira de costumes. Com A Grande Guerra, o diretor consagrou-se como referência na cinematografia mundial ao realizar uma das primeiras produções na Itália a desviar do padrão e retratar a primeira guerra fora dos moldes fascistas de representação. A partir de uma análise de seus recursos narrativos e dispositivos visuais, essa comunicação busca explorar as conexões que o filme de Monicelli estabelece com a história, particularmente em relação à retórica de propaganda do cinema da era fascista.
\end{abstract}

Palavras-chave: Mario Monicelli; A Grande Guerra; cinema italiano.

\begin{abstract}
This work aims to investigate the film The Great War (1959), by Italian director Mario Monicelli. Accused of anti-patriotism at the time of its release, the work revisits the conflicts of World War I in a cynical and tragicomic record. Monicelli is considered one of the most expressive names in the Commedia all'italiana genre, a popular style that dominated Italian cinema in the 1960s and 1970s, characterized by social criticism and moral satire. With The Great War, the director established himself as a reference in world cinematography by making one of the first productions in Italy to deviate from the standard and portray the first war outside the fascist molds of representation. From an analysis of its narrative resources and visual devices, this essay seeks to explore the connections Monicelli's film establishes with history, particularly in relation to the propaganda rhetoric of the fascist era cinema.
\end{abstract}

Key words: Mario Monicelli; The Great War; Italian cinema

1 Graduada em Letras pela Universidade Federal de Minas Gerais e mestra em Estudos Literários de língua inglesa pela mesma instituição. 
Mario Monicelli é considerado um dos nomes mais expressivos do cinema italiano como um todo, e mais especificamente do gênero das Commedia all'italiana. Trabalhou como diretor, produtor e roteirista. O cineasta foi responsável por uma extensa produção contando com quase 70 filmes dirigidos, desde 1935 a 2006. Juntamente com outros diretores consagrados de seu tempo, como Vittorio de Sica, Pietro Germi, Dino Risi e outros, Monicelli realizou obras que marcaram um período da indústria cinematográfica italiana com filmes que posteriormente foram intitulados de commedia all'italiana. Sucessor do movimento neorrealista, o gênero caracterizou-se por um estilo de matriz popular que dominou o cinema italiano entre as décadas de 60 a 70, uma forma de comédia na qual se inserem elementos dramáticos, assinalada pela crítica social e sátira de costumes. Estes são atributos determinantes na cinematografia de Monicelli, que é visto por críticos como o pai das comédias à italiana por ter dirigido obras fundantes do gênero no fim dos anos 50. Este trabalho pretende investigar A grande guerra de Monicelli, do ano de 1959, examinando a maneira com que seus recursos narrativos e dispositivos visuais agem como um contraponto às construções ficcionais da primeira guerra vista pelas lentes da produção cinematográfica fascista.

Com A grande guerra, o diretor influenciou amplamente a produção fílmica do pós-guerra na Itália ao instaurar uma tendência revisionista e lidar com o passado e memória cultural da primeira guerra. Conforme aponta a crítica Marcia Landy em seu Cinema and counter-history, muitas das comédias italianas desse período lançavam-se ao esforço de revisitar "ficções herdadas do passado cultural e político da Itália"2 (LANDY, 2015, p. 95). O controverso projeto do diretor retoma, assim, o evento histórico, fornecendo a base para uma reflexão sobre essas "ficções herdadas" no campo audiovisual em seu país.

Acusada de anti-patriotismo à época de seu lançamento, a obra enfrentou problemas com a censura por revisitar os conflitos da Primeira Guerra Mundial em um registro cínico, tragicômico, farsesco, além de sustentar uma retórica anti-militarista. Monicelli, já reconhecido nacionalmente pelo sucesso comercial Os Eternos Desconhecidos (I soliti ignoti, 1958) consagrou-se como referência na cinematografia mundial a partir desse filme, por realizar uma das primeiras produções na Itália a desviar do padrão estabelecido e retratar, com humor, a Primeira Guerra fora dos moldes fascistas de representação.

A trama, através de um estilo que oscila entre o tratamento cômico e situações dramáticas, acompanha um grupo de soldados no front, estruturada por episódios ou esquetes que procuram destacar as tarefas mundanas que constituem o cotidiano desses combatentes. A grande guerra nos traz, de antemão, Giovanni Busacca e Oreste Jacovacci (interpretados por grandes ícones do cinema italiano, Vittorio Gassmann e Alberto Sordi), dois protagonistas insubordinados, vigaristas, desonestos, individualistas, ineptos e que agem apenas em nome da autopreservação. Giovani e Oreste, convocados para o exército a contragosto e desprovidos de um senso de dever, se encontram continuamente no limiar da deserção.

Ao se conhecerem no dia do alistamento, Giovani suborna Oreste para que o ajude a não ser convocado. Oreste, por sua vez, mente que vai ajudá-lo e embolsa o dinheiro sem fazer nenhum esforço pelo colega. Com um desempenho medíocre como combatentes e desdém pelas autoridades, ambos passam a narrativa buscando esquivar-se de suas atribuições e estar sempre em vantagem. Como demonstram as sequências em que eles abarrotam suas mochilas com palha durante o trei-

2 inherited fictions of Italy's cultural and political past 
namento militar para evitar carregar peso, distraem um colega para furtar um cigarro de seu bolso, desobedecem ordens diretas pra deitar na grama e distinguir formas nas nuvens, enganam os oponentes alemães para que atirem em uma panela e eles possam cozinhar castanhas ou fingem arrecadar fundos em uma festa para os soldados que não puderam comparecer com a verdadeira intenção de viajar para a cidade vizinha e gastar o dinheiro adquirido com bebida alcóolica e mulheres.

Os dois protagonistas cômicos de A grande guerra, pela sua covardia e ausência de idealismo, foram criticados severamente pelo governo italiano e veículos de comunicação por expôr as forças armadas ao ridículo e ao retratá-los como homens comuns com falhas e fraquezas. Conforme destaca Mira Liehm: "Como em suas comédias anteriores, Monicelli criou figuras simpáticas de dois italianos comuns em desacordo com as leis do mundo"3 (LIEHM, 1984, p. 163). Giovanni e Oreste se afastam do paradigma fascista do soldado exemplar, aquele que valoriza a coragem, a valentia, a lealdade e a honra, propenso a grandes feitos, devoção à pátria e a gestos sacrificiais em benefício da nação. Assim eram representados os heróis da ficção de guerra da era do regime. "O filme de Monicelli foi o primeiro a desmitificar o controverso papel e desempenho da Itália na Primeira Guerra Mundial. Desde o início, a guerra foi glorificada como uma grande luta patriótica pela grandeza nacional e gradualmente se tornou uma lenda do heroísmo italiano incondicional" 4 (LIEH, 1984, p. 163). O argumento da crítica oferece uma perspectiva interessante para se pensar a questão da construção de personagem no trabalho de Mario Monicelli.

$\mathrm{Na}$ comédia desenvolvida pelo diretor, observa-se, sobretudo, o interesse em colocar em evidência figuras desajustadas e à margem enfrentando circunstâncias adversas. Monicelli registra, com empatia, o indivíduo derrotado, o homem ordinário massacrado e subjugado pelas instituições ou, como destacado por Andrea Bini, há em seu olhar "um afeto especial pelos excluídos que Monicelli nunca abandonou ao longo de sua longa carreira" ${ }^{5}$. A aproximação dessa realidade social está vinculada à tradição do neorrealismo, já que nele também se elege um "interesse em pessoas desamparadas que se empenham para sobreviver em uma sociedade hostil” (BINI, 2016, p. 62). ${ }^{6}$ Cabe ressaltar, assim, que a centralidade dada pelo cineasta a esse perfil de personagem não só evoca um padrão do cinema neorrealista, como também exerce uma função política ao subverter formas narrativas consolidadas do regime fascista.

A grande guerra rejeita uma visão positiva e engrandecedora do serviço militar. Antes disso, abordar o tema da Primeira Guerra pós-colapso do fascismo em uma chave irônica era interdito. Ao anunciar que faria uma comédia sobre esse evento histórico, o diretor foi amplamente criticado pela mídia e por camadas mais conservadoras da sociedade italiana. Ainda nos estágios iniciais das filmagens, o produtor do filme conseguiu auxílio do Ministério da Defesa, que havia se comprometido a emprestar armas e tanques à equipe. No entanto, órgão optou por retirar seu apoio ao descobrir o posicionamento da imprensa. Vários artigos foram publicados à época, acusando Monicelli

3 As in his previous comedies, Monicelli created appealing figures of two common Italians at odds with the laws of the world

4 Monicelli's film was the first to desmitify Italy's controversial role and performance in World War I. From the outset, the war was glorified as a great patriotic struggle for national grandeur and gradually became a legend of unconditional Italian heroism

5 a special affection for the outsiders that Monicelli never abandoned throughout his long career

6 interest in destitute people who strive to survive in a hostile society 
e seu produtor de satirizar e prejudicar a imagem daqueles que se sacrificaram nas fronteiras da Itália. Como se recorda o cineasta:

O cinema, o teatro e a imprensa italianos eram proibidos de falar da Grande Guerra em outros termos que não fossem lisonjeiros. Depois que as notícias sobre meu filme foram divulgadas, a imprensa (...) publicou artigos escritos por jornalistas conhecidos que exigiam que o filme fosse interrompido. Foi lançada uma grande campanha: "Monicelli, [seus roteiristas] Age e Scarpelli desonrarão os seiscentos mil mortos da Primeira Guerra Mundial"7(MONICELLI apud LIEHM, 1984, p. 163)

Apesar disso, o filme foi concluído ainda assim e eventualmente alcançou prestígio por trazer à tona uma página ainda intocada da história italiana depois da queda do regime e oferecer um contraponto ao discurso oficialmente difundido pela ideologia fascista.

Com o objetivo declarado de elevar a moral das tropas e do público, as narrativas da era fascista possuíam um cunho marcadamente escapista e fins propagandísticos, em que se predominavam desfechos felizes e ímpetos patrióticos por meio de um tom triunfalista. Em contrapartida, o cinema de Monicelli, ao aliar comédia e história, assume um tom crítico como forma de se distanciar das glorificações da guerra realizadas por seus predecessores fascistas e operar um deslocamento contrário às visões do regime de exaltação de valores nacionais. Esses filmes, para além do cinema de ficção e estendendo-se também aos documentários, reportagens e cinejornais exibidos em sessões, se amparavam na criação de imagens palatáveis e sanitizadas da guerra para o consumo do público. Sendo assim, a ação nas trincheiras não era considerada um tópico apropriado para exibição, que geralmente se concentrava mais na artilharia e frentes de apoio e provisões, ou seja, em atividades militares auxiliares, conferindo destaque às celebrações após as vitórias italianas em batalhas. Sobre essa "estabilização da memória da Grande Guerra", Marie-France Courriol escreve: "Em 1935, precisamente quando o cinema de ficção italiano começou a verdadeiramente abordar o assunto, o regime fascista já havia se apropriado da memória da Primeira Guerra Mundial, e sua ligação a esse evento fundamental havia se tornado um leitmotiv do discurso político"8 (COURRIOL, 2014, p. 347). A tendência da produção audiovisual do país naquele momento era, logo, de "comemorar em excesso seus triunfos e ocultar seus fracassos" (CINQUEGRANI, 2014 p. 324), sustentando uma ficção de omissão.

O próprio Monicelli, que trabalhou na indústria durante a era fascista como assistente de direção e roteirista, narrava os obstáculos encontrados para a realização dos filmes. Como os estúdios eram controlados por Benito Mussolini, em alguns casos as filmagens eram supervisionadas por um oficial do governo apto a fazer intervenções. E Monicelli afirmava que o conteúdo produzi-

7 The Italian cinema, theater and press were prohibited from speaking of the Great War in other than flattering terms. After the news about my film was made public, the press (...) published articles written by well-known journalists who demanded that the film be stopped. A huge campaign was launched: "Monicelli, [his scriptwriters] Age and Scarpelli will dishonor the six hundred thousand dead of World War I

8 In 1935, precisely when Italian fiction cinema began to fully tackle the subject, the Fascist regime had already secured its hold on the memory of WWI, and its link to this fundamental event had become a leitmotif of political discourse 
do nessas condições deveria ser denominado de "cinema de evasão", "onde não podiam haver problemas (...) e se valorizava bons sentimentos, atos de coragem e ações edificantes" ${ }^{10}$ (MONICELLI apud MANCINI, 1980, p'. 55). Nesse contexto de coerção política e restrição de liberdades artísticas, o código de censura declarava que qualquer temática que viesse a ser considerada "ofensiva ao prestígio das instituições e figuras de autoridade que governavam a Itália, as forças armadas ou cidadãos privados"11 (MANCINI, 1980, p. 55) não seria aceita.

Entretanto, já na sequência de abertura do filme de Monicelli, vemos imagens da guerra que se opõe às construções ficcionais prévias que também abordavam a Primeira Guerra Mundial no cinema italiano. Durante os créditos iniciais (ver figuras 1, 2 e 3), ao invés de oferecer ao espectador cenas de soldados em marcha, em combate, empunhando armas ou executando qualquer forma de ação militar, o que vemos é uma sucessão atividades prosaicas e triviais, como soldados cortando uma fatia de pão, enrolando um cigarro, enchendo seus cantis, costurando um botão, recebendo um prato de sopa ou com os pés afundando em lama. Esses planos nos mostram as tropas em toda sua banalidade e precariedade e retira delas, logo de início, qualquer dimensão grandiosa, épica ou heroica

O filme também busca produzir relações de intertextualidade com a mídia e imprensa do período fascista, sempre estabelecendo uma distinção entre o discurso sendo promovido por esses veículos e o discurso do filme. Um dos personagens é obcecado por Francesca Bertini, atriz conhecida por sua carreira sólida no cinema da era fascista. Como ressalta Maurizio Cinquegrani: "os filmes de ficção feitos durante a guerra dificilmente evocavam a sensação de aniquilação que caracterizava os campos de batalha. A produção de filmes italianos durante a guerra foi dominada por narrativas melodramáticas e sensacionalistas, estrelando atrizes famosas como Lydia Borelli e Francesca Bertini” (CINQUEGRANI, 2014, p. 327). E quando o soldado está discutindo com outro colega sobre os papéis de Bertini em alguns filmes, este simplesmente retruca "mas isso não é assim na vida real". Ainda que possa ser considerada não mais do que uma fala banal sobre o descompasso entre o glamour das telas e a realidade cotidiana, ela também nos permite fazer uma leitura desse comentário como um aceno do filme ao cinema da época do regime, sempre alheio aos conflitos sociais do país. Parece pertinente, inclusive, destacar que essa é precisamente a sequência que antecede a partida do batalhão para as trincheiras.

Outra ilustração significativa ao endereçamento feito aos suportes de comunicação se dá quando os soldados esfomeados e cheios de piolho se protegem de uma chuva em um abrigo precário. Um deles segura o jornal Domenica del Corriere, cuja ilustração de capa retrata os soldados sentados diante de uma lareira, celebrando o Natal em seu alojamento. O homem que segura o jornal diz "Está vendo? Estes somos nós. Estamos dentro de uma casa, todos contentes" e em seguida lê a matéria, que descreve o período de trégua entre as operações como um momento em que estão "todos em volta dos aquecedores de campo, matando as horas com músicas e canções". A organização visual do plano constitui quase um mise en abyme às avessas, uma vez que a narrativa que está

9 a cinema of evasion

10 could not exist problems (...) The greatest emphasis was given to the good sentiments, to courageous acts, to the more edifying things

11 offensive to the prestige of the institutions and figures of authority that governed Italy, the armed forces or private citizens 
contida dentro da outra contradiz a primeira (ver figura 4 e 5). Em vez de um efeito de duplicação o que se forma é um desacordo entre as duas composições, um encaixe de níveis narrativos que se confrontam, camadas que são colocadas em crise. Esse é dos planos que atua de forma mais emblemática em A grande guerra, na medida em que emprega recursos expressivos da linguagem cinematográfica, como o enquadramento, para expôr a construção romantizada da Primeira Guerra feita pelos meios de comunicação instrumentalizados pelo governo italiano. Percebe-se, ainda, na cena ilustrada na capa da revista e em sua descrição, a ideia de coesão social defendida pela ideologia fascista. Courriol argumenta: "Um elemento fundador da cultura política do fascismo, a memória da Primeira Guerra Mundial foi construída sobre uma memória seletiva do conflito, purgada violentamente de seus elementos perturbadores"12 (COURRIOL, 2014, p. 346) Afinal, promoviam-se ideais ilusórios de união entre as classes e um sentido fictício de solidariedade, em um empenho de vender o mito da unidade nacional que insinuava que todas as camadas sociais e todos os homens estavam unidos na guerra em colaboração harmoniosa

Entretanto, um dos elementos recorrentes no trabalho de Monicelli são as divisões regionais que delimitam o território italiano. É marcado no filme esse embate cultural entre as várias regiões da Itália. Convém sublinhar que há um contraste socioeconômico e político, historicamente constituído, entre o norte e o sul da península, tendo como eixo principal a oposição entre norte industrializado e sul agrário. "A dimensão regional da guerra era frequentemente enfatizada no cinema através do uso do dialeto"13 (CINQUEGRANI, 2014, p. 328), aponta Cinquegrani sobre produções italianas da época. Em A grande guerra, a narrativa salienta o tensionamento entre esses pólos, uma vez que cada personagem assume para si sua identidade local, instituindo os soldados de outras origens dentro da própria Itália como um outro a ser hostilizado ou. Isso se estabelece desde o início da trama através dos dois personagens principais, visto que um é de Roma e o outro de Milão, característica que é trabalhada na forma de contrastes reiterados. Ao longo da narrativa, Giovanni e Oreste se provocam repetidamente, baseando-se nos estereótipos que definem os romanos e os milaneses. No momento em que se conhecem, logo na primeira troca entre eles o Giovanni já declara 'ah, você é romano', carregando em sua fala uma nota de distanciamento e desconfiança. Além disso, a própria linguagem enunciada pelos seus personagens reflete essa perspectiva fragmentada da nação italiana com o uso frequente de dialetos e sotaques que agem como uma barreira linguística entre os soldados.

No filme, é comum haver desentendimentos e confusões entre os indivíduos em razão dessas variantes do idioma. De tal maneira que, próximo ao desfecho, Giovanni e Oreste se abrigam em um celeiro para se esconderem e ouvem vozes de pessoas se aproximando. Oreste ouve atentamente, reconhece algumas palavras e então diz, baseando-se na forma que os ouviu pronunciar as palavras, que "Eles são de Bergamo, são nossos companheiros", mas Giovanni o corrige dizendo que na verdade se trata do inimigo austríaco. Ou seja, o filme progressivamente constrói situações em que ocorrem estranhamentos e falhas na comunicação entre os falantes de suas respectivas comunidades regionais, a ponto de cometerem o equívoco de achar que os austríacos são italianos.

12 A founding element of Fascism's political culture, the memory of the First World War was therefore constructed on a selective memory of the conflict, violently purged of its disturbing elements

13 The regional dimension of the war was often emphasised in film through the use of dialect 
A grande guerra encerra com uma conclusão ambígua, colocando o espectador diante de uma morte supostamente heróica dos dois protagonistas, que escolhem o sacrifício à traição de sua unidade militar. Giovanni e Oreste são capturados pelo inimigo austríaco e revelam, acidentalmente, um plano de ataque que estava sendo arquitetado pelo seu regimento. Ao perceberem o deslize, decidem negam-se a fornecer informações mais detalhadas sobre a localização exata do batalhão, mesmo sob ameaças do comandante de fuzilamento. O plano seguinte exibe as tropas italianas em batalha, enfrentando uma dura derrota. Um dos soldados comenta: "E pensar que aqueles dois conseguiram se safar!". A recusa dos protagonistas os condena a execução, mas esse gesto derradeiro de altruísmo permanece no anonimato e ambos morrem com a reputação de preguiçosos e insolentes. É inevitável refletir sobre essa trajetória dos personagens, do esforço de deserção à morte heróica, como um ato final de redenção. Um exame mais atento, porém, dos traços definidores da comédia de Monicelli nos permite pensar que esse desfecho preocupa-se menos em validar a virtude inerente dos combatentes italianos do que salientar o senso de humor sombrio cínico e sombrio característico das obras do cineasta. Sobre o cinema de Monicelli, Andrea Bini sugere que ele, com sua visão cínica da sociedade italiana, "critica o otimismo social do neorrealismo rosa e narra o fracasso da esperança neorrealista de reconstruir o país em torno de um novo conjunto de valores humanitários"14 (BINI, 2016, p. 69). Assim, o feito corajoso de Giovanni e Oreste esvazia-se de qualquer significado solene para dar lugar a um sentimento de desesperança e impossibilidade que permeava não só os filmes do diretor, mas muitas das commedias all'italiana como um todo.

Ao explorar as conexões que Monicelli estabelece com a história em A grande guerra, observa-se que o diretor explora o legado cultural da retórica fascista no cinema italiano. Como uma ferramenta política de controle social, as produções cinematográficas dessa era se articulavam a partir de uma perspectiva nacionalista que representava os oficiais do exército e os campos de batalha de forma romântica e higienizada, tendo a finalidade de instituir o consenso sobre a memória nacional da Primeira Guerra e deter uma versão unívoca do conflito.

A obra de Monicelli recusa esse pensamento do regime ao não omitir os horrores da guerra, incluindo em sua narrativa as ruínas e os destroços, os feridos e os mortos. Seu filme pacifista propõe uma reflexão sobre o lugar do cinema de ficção no imaginário italiano do pós-guerra, uma vez que se insere na cinematografia de seu país como um dos primeiros trabalhos a oferecer uma contestação frontal do mito fascista da primeira guerra.

14 criticizes the social optimism of pink neorealism and narrates the failure of neorealist hope to rebuild the country around a new set of humanitarian values 


\section{REFERÊNCIAS BIBLIOGRÁFICAS}

BINI, Andrea. Male Anxiety and Psychopathology in Film: Comedy Italian Style. [S. l.]: Springer, 2016.

CINQUEGRANI, Maurizio. Place, Time and Memory in Italian Cinema of the Great War. In: LÖSCHNIGG, Martin; SOKOLOWSKA-PARYZ, Marzena. The Great War in Post-Memory Literature and Film. [S. l.]: Walter de Gruyter GmbH \& Co KG, 2014.

COURRIOL, Marie-France. Looking back on the myth of the Great War: Anti-rhetoric, war culture and film in Fascist Italy. Media, War \& Conflict, SAGE Publications, v. 7, n. 3, 2014. Disponível em: sagepub.co.uk. Acesso em: 20 ago. 2018.

LANDY, Marcia. Cinema and Counter-History. 2. ed. Indiana University Press, 2015.

LIEHM, Mira. Passion and defiance: film in Italy from 1942 to the present. University of California Press, 1984.

MANCINI, Elaine. Film Weapons For and Against the Regime: 1935 in Italy. Oxford Art Journal: Propaganda, Oxford University Press, 1980. Disponível em: http://www.jstor.org/stable/1360219. Acesso em: 19 set. 2019.

YOUNG, Deborah; MONICELLI, Mario. Poverty, Misery, War and Other Comic Material: An Interview with Mario Monicelli. Cinéaste, Cineaste Publishers, Inc., v. 29, n. 4, 2004. 
LISTA DE IMAGENS

Figura 1

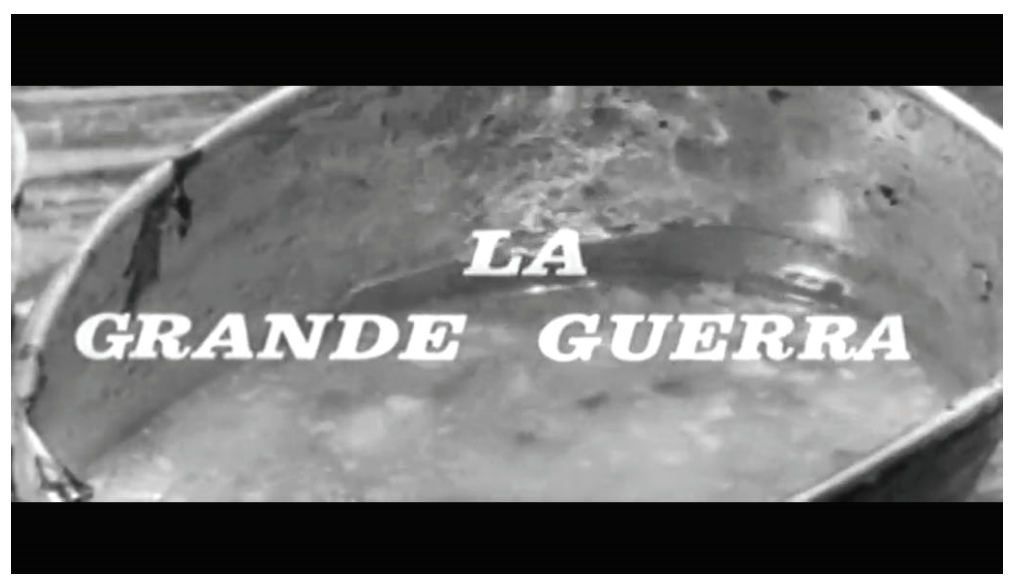

Figura 2

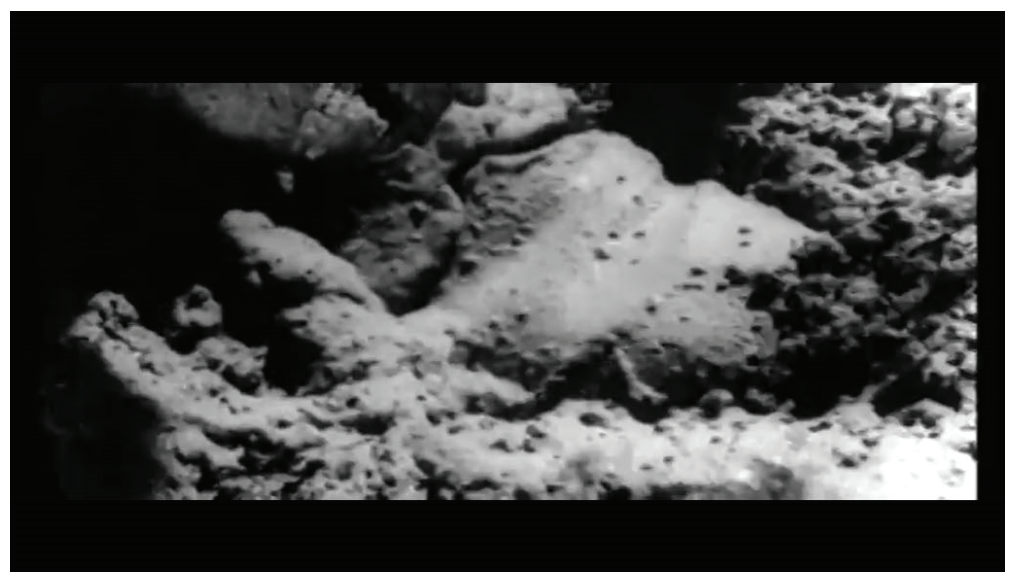

Figura 3

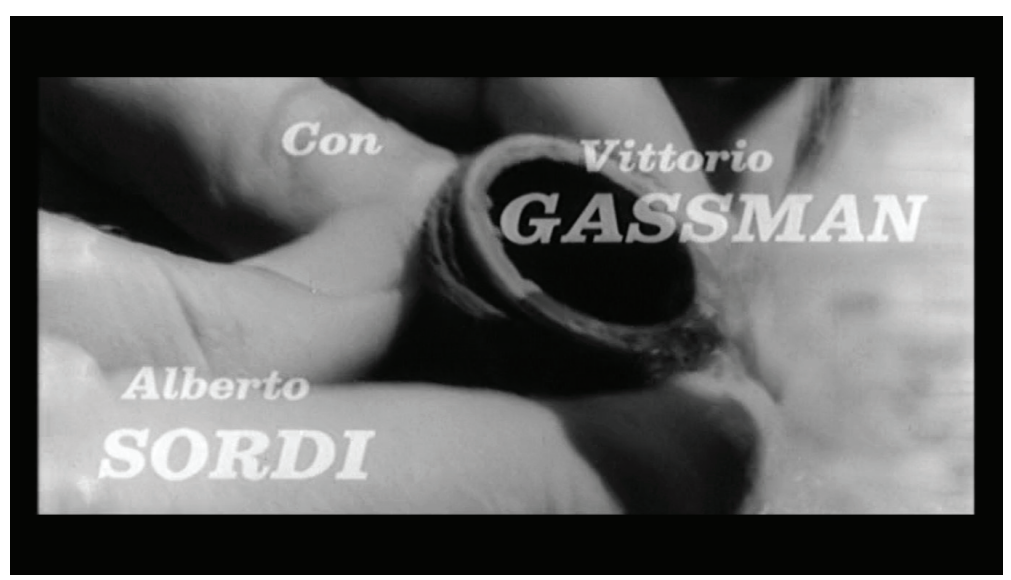


Figura 4

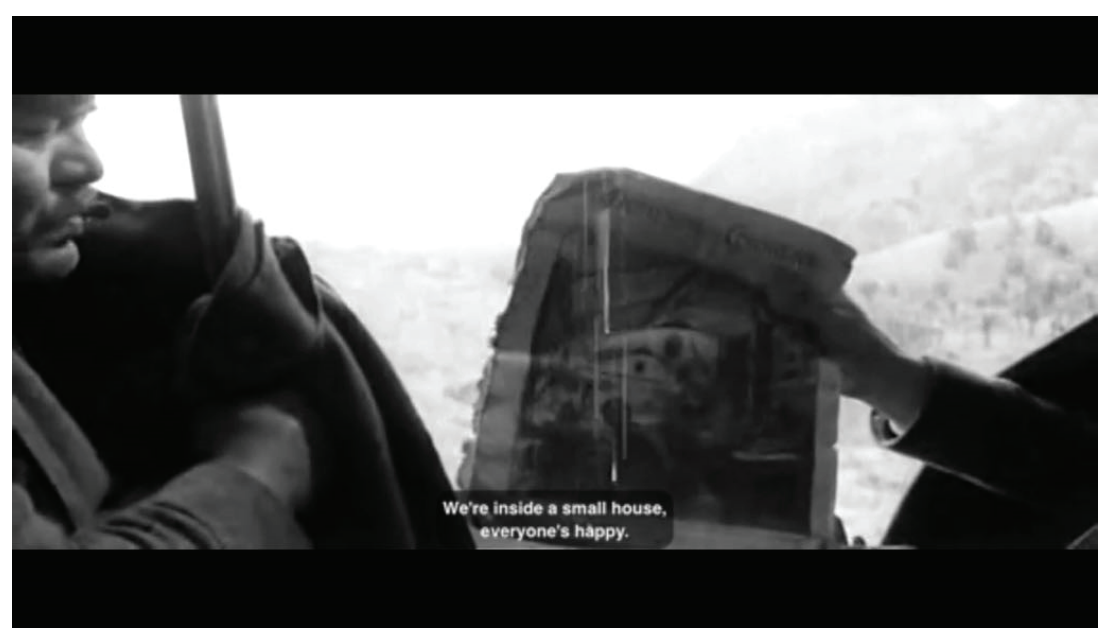

Figura 5

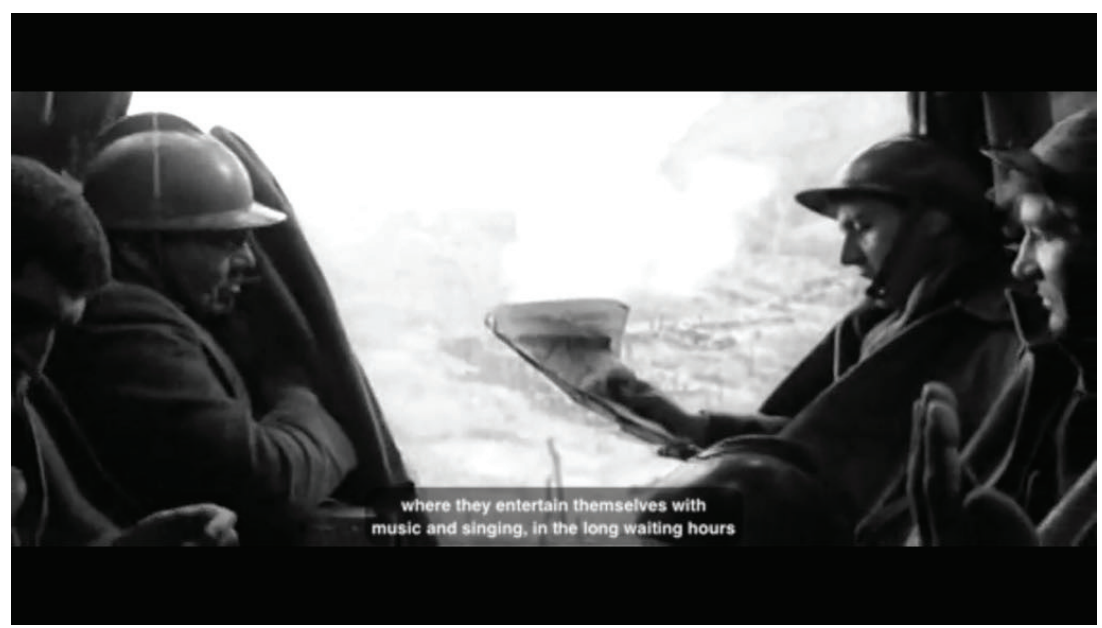

